\title{
ITINERÁRIOS TERAPÊUTICOS DE PACIENTES COM CÂNCER DE BOCA ATENDIDOS NO HOSPITAL DE CLÍNICAS DA UNICAMP
}

\section{Anabel Vizcaino Otero*, Maria da Graça G. Andrade.}

Resumo

Estudo qualitativo sobre os itinerários terapêuticos percorridos por pacientes com câncer de boca nas redes de saúde até sua admissão no serviço oncológico de referência regional.

\section{Palavras-chave: Câncer da Cavidade Oral, Acesso aos Serviços de Saúde, Rede Prestadora de Serviços de Saúde}

\section{Introdução}

O câncer constitui um importante problema de Saúde Pública no Brasil e no mundo. O câncer de boca é o $5^{\circ}$ em incidência entre homens e abrange as neoplasias malignas com localização primária nos lábios, cavidade oral, glândulas salivares e orofaringe, sendo o tabaco e o álcool os principais fatores de risco implicados na carcinogênese ${ }^{1}$. O diagnóstico muitas vezes é tardio, o que reduz a sobrevida e produz consequências funcionais e psicossociais que pioram a qualidade de vida dos sujeitos. A reconstituição dos itinerários terapêuticos dos pacientes em busca de atenção à saúde pode subsidiar processos de organização e gestão de serviços de saúde, possibilitando a construção de práticas assistenciais compreensivas e contextualmente integradas. O estudo objetivou caracterizar as redes assistenciais utilizadas e a experiência de acesso aos serviços da rede pública de saúde, incluindo os recursos procurados pelos pacientes, as razões que motivaram suas escolhas e os intervalos de tempo entre a procura por atendimento, a confirmação diagnóstica e o início do tratamento. Foi realizada a análise temática do conteúdo colhido em entrevistas semiestruturadas e consulta a prontuários médicos de 23 pacientes em seguimento no ambulatório de Otorrinolaringologia do HC/UNICAMP, no período de outubro de 2018 a junho de 2019.

Projeto aprovado pelo CEP/Unicamp, CAAE $n^{\circ}$ 95515118.0.0000.5404

\section{Resultados e Discussão}

Perfil Sociodemográfico dos participantes: a média de idade à ocasião da pesquisa foi de 64,5 anos (variação de 58 a 81 anos), 82,6\% eram homens, com ensino fundamental incompleto, aposentados, todos usuários exclusivos do SUS, procedentes principalmente da região Metropolitana de Campinas, mas também de outras cidades do Estado de São Paulo e de Minas Gerais.

Os sintomas que motivaram a procura por serviço de saúde foram diversos, prevalecendo lesões em cavidade oral, mas queixas na orofaringe e pescoço também foram relatadas. A maioria dos itinerários compreendem um período assistencial de até cinco anos.

Dentre os serviços de saúde inicialmente procurados, destaca-se a Unidade Básica como o principal ponto de partida nos itinerários percorridos, ainda que também tenham sido procurados policlínicas médicas, centro odontológico, clínicas particulares e até farmácia.

A maior parte dos itinerários terapêuticos foram compostos exclusivamente por serviços da rede pública, porém em 5 dos 23 casos houve um mix público-privado, sobretudo para agilizar a realização da biópsia. Os itinerários envolveram centros de especialidade médica e odontológica, assim como hospitais públicos, como Hospital de Sumaré e Ouro Verde em Campinas. A análise dos percursos revelou inexistência de fluxos regulares na rede de serviços, mesmo nos casos em que a UBS esteve envolvida, gerando iniciativas de intermediação dos próprios pacientes ou familiares para obter acesso ao serviço oncológico. O perfil do estadiamento mostrou que mais da metade dos pacientes foram diagnosticados em estadios avançados da doença (III e IV), o que possivelmente decorre da demora para diagnóstico, embora não se tenha obtido dados que permitissem inferir o intervalo de tempo médio entre a procura por atendimento e a realização da biópsia.

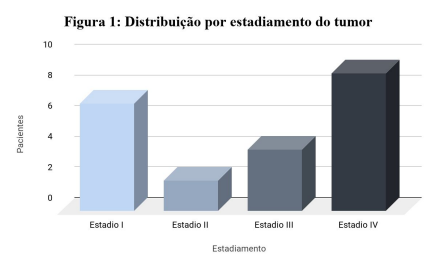

O intervalo de tempo entre o diagnóstico e o início do tratamento foi bastante variável, com extremos de 14 a 324 dias, e, em apenas 5 dos 23 casos, esse intervalo ocorreu abaixo dos 60 dias estipulados por lei².

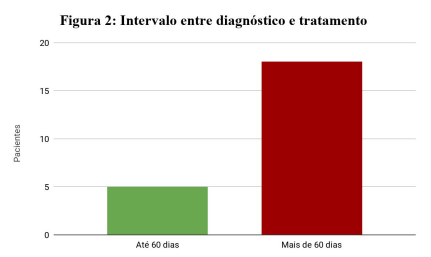

\section{Conclusões}

Os itinerários terapêuticos revelaram que os pacientes encontram muitas dificuldades para percorrer os pontos assistenciais da rede de saúde até chegarem ao serviço oncológico de referência, com fluxos ineficientes, pouca integração entre os serviços, diagnósticos tardios e demora para início do tratamento oncológico.

\section{Agradecimentos}

Aos pacientes que compartilharam sua história; aos profissionais do Ambulatório de Otorrinolaringologia do HC. Ao CNPq pela bolsa de Iniciação Científica.

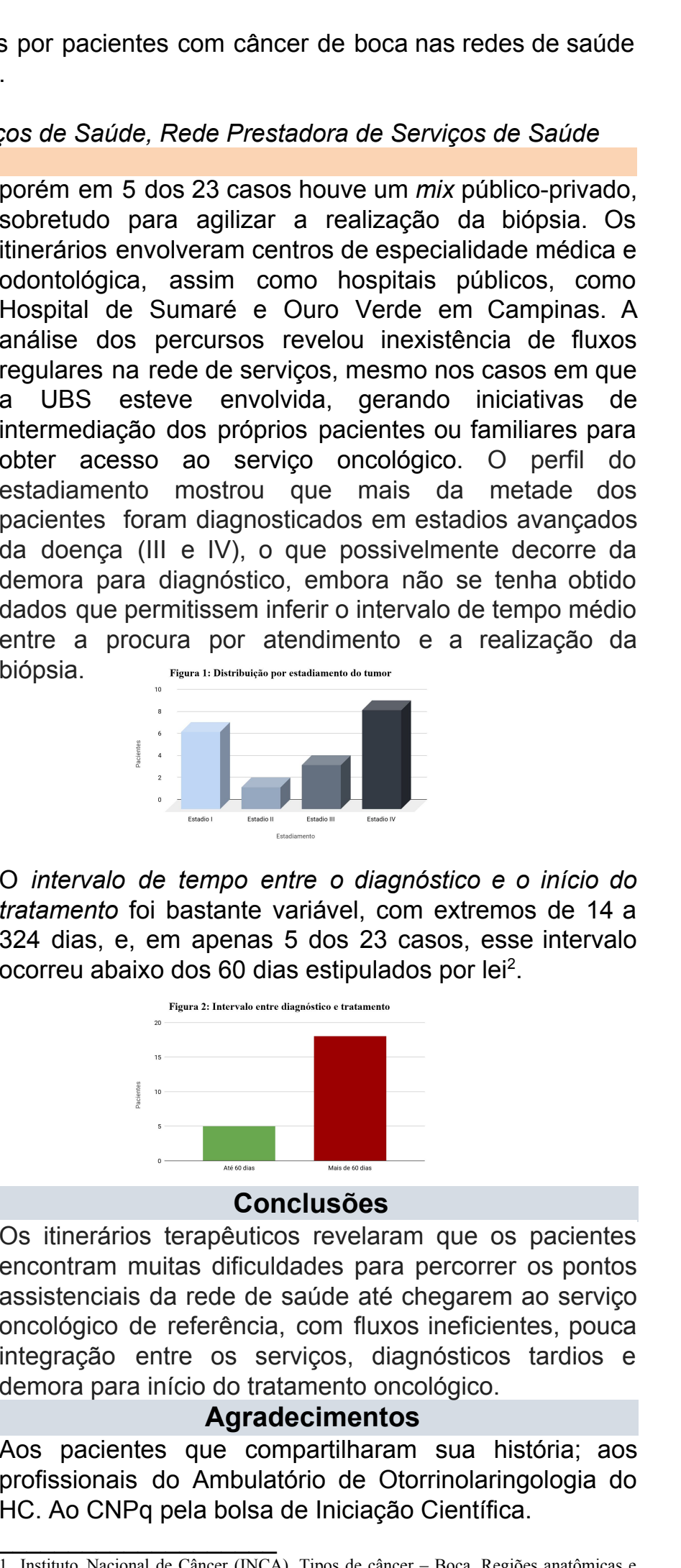

.

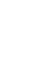

